\title{
Chronic undernutrition and the aged
}

\author{
BY MARIANNE SCHROLL, LILLIAN JøRGENSEN, MERET'E \\ OSLER AND MICHAEL DAVIDSEN \\ Copenhagen University and Department of Geriatrics, Copenhagen City Hospital, Oester \\ Farimagsgade 5, 1399 Copenhagen K, Denmark
}

\begin{abstract}
According to Scrimshaw (1989) the nutritional problems of the elderly are most comprehensively viewed in the light of the classical epidemiological triad of host, agent and environment. The host factors are biological changes with age, and the effects of disease. The agent factors are the deficiencies of dietary energy and specific nutrients. The environment modifies the interaction of host and agent through living conditions and lifestyle factors. The level of risk for chronic undernutrition varies greatly with geographical and socio-economic groups and among individuals.

In one European and two Danish dietary surveys chronic undernutrition was related to age, health and lifestyle.
\end{abstract}

\section{METHODS}

The purpose of the surveys was to identify population groups at risk from a nutritional point of view, and to study relationships between diet, health and disease.

\section{The Danish Dietary Survey 1985}

A nationwide dietary survey was carried out in 1985 by the Danish National Food Agency (1987). The survey included 2242 persons, 15-80 years old, who constitute a representative sample of the adult Danish population. Diet information was obtained by personal interview using the diet history method. A thoroughly structured and precoded interview form was used and food models were used for estimating portion sizes.

\section{The Danish Glostrup Population Studies}

These studies include dietary information on 1022 men and 1034 women aged 30, 40, 50, 60,70 and 85 years, representative of the population in Copenhagen County and, thereby, a high proportion of the Danish population (Jørgensen et al. 1991). The information was collected in the period $1982-4$ by $7 \mathrm{~d}$ food records.

\section{The SENECA Survey}

This survey was an initiative of EC/Euronut, a European Community project on nutrition and health in the elderly started in 1988 with nineteen research groups working on the major nutritional issues affecting the growing number of elderly persons in Europe (Groot et al. 1991a,b,c,d,e). Using standardized methodology, information has been collected on the dietary intake, nutritional status, physical activity, lifestyle, health and performance of about 2500 people born between 1913 and 1918. These findings are to be used as the basis for a follow-up study in 1993. A modified dietary history was used 
Table 1. Definitions of malnutrition used in these studies

\begin{tabular}{ll}
\hline $\begin{array}{l}\text { Body composition } \\
\text { BMI }\end{array}$ & $<20 \mathrm{~kg} / \mathrm{m}^{2}$ and $\geqslant 30 \mathrm{~kg} / \mathrm{m}^{2}$ \\
& \\
Daily intakes of nutrients & $<400 \mathrm{mg}$ \\
$\mathrm{Ca}$ & $<7 \mathrm{mg}$ for men, $<5 \mathrm{mg}$ for women \\
$\mathrm{Fe}$ & $<600 \mu \mathrm{g}$ \\
$\mathrm{Vitamin} \mathrm{A}$ & $<0 \cdot 15$ \\
$\mathrm{P}: \mathrm{S}$ & $<49 \mathrm{~g}$ for men, $<42 \mathrm{~g}$ for women \\
Protein & $>50 \%$ \\
Fat: Energy as fat & $>15 \%$ \\
Energy as saturated fat & $<7.7 \mathrm{MJ}$ for men, $<6.6 \mathrm{MJ}$ for women \\
Energy & $<1.0$ \\
P+M:S & $>1.1 \mathrm{mg}$ for men, $<0.9 \mathrm{mg}$ for women \\
Pyridoxine & $>10 \%$ of energy as mono- and disaccharides \\
Sugar &
\end{tabular}

to assess food consumption and local food tables were used to derive estimates of nutrient intakes.

Chronic undernutrition was assessed by comparison of energy and nutrient intakes in relation to lower limits for safe intake of nutrients per person per d. Limits were mainly set at about two-thirds of the intake of the Danish recommended dietary allowances (RDA; Danish National Food Agency, 1989). Values for the lowest intake were used exclusively in the evaluation of results from nutritional surveys. People with intakes consistently below these values were deemed to be at risk of malnutrition symptoms. As the nutrition problems in Denmark are seldom genuine undernutrition, the limits have been set to define 'diets with a low nutrient density'. The nutrient content can be low even in some cases of overeating. Thus, high intakes of fat or sugar have been used as indicators of 'malnutrition'. The criteria of malnutrition are shown in Table 1.

\section{RESULTS}

\section{Age and chronic undernutrition}

Age is a relatively poor predictor of chronic malnutrition.

Body composition and age. The percentage of people who had body mass index, BMI (weight/height ${ }^{2}$ ) $<20 \mathrm{~kg} / \mathrm{m}^{2}$ decreased across the age-groups $30-60$ years in the Glostrup population studies and increased in the 70 year olds to $6.7 \%$ of men and $10.3 \%$ of women. As age increased so did the percentage of obese people. Of 30-year-old women $2 \cdot 1 \%$ were severely obese $\left(B M I \geqslant 30 \mathrm{~kg} / \mathrm{m}^{2}\right)$ compared with $11.5 \%$ of the 70 -year-old women.

Energy and age. Energy intake of men decreased significantly across the age-groups $30-85(11 \cdot 6-8 \cdot 3 \mathrm{MJ} / \mathrm{d})$, but the decrease was less for women $(8 \cdot 0-6 \cdot 3 \mathrm{MJ} / \mathrm{d})$. The median energy distribution between fat, carbohydrate, sugar, protein and alcohol was the same in the different sex and age-groups.

Nutrient intake and age. The average daily intakes of vitamins, minerals and some trace elements (thiamin, pyridoxine, folate, $\mathrm{Ca}, \mathrm{Fe}, \mathrm{Zn}$ and I) decreased with age. 


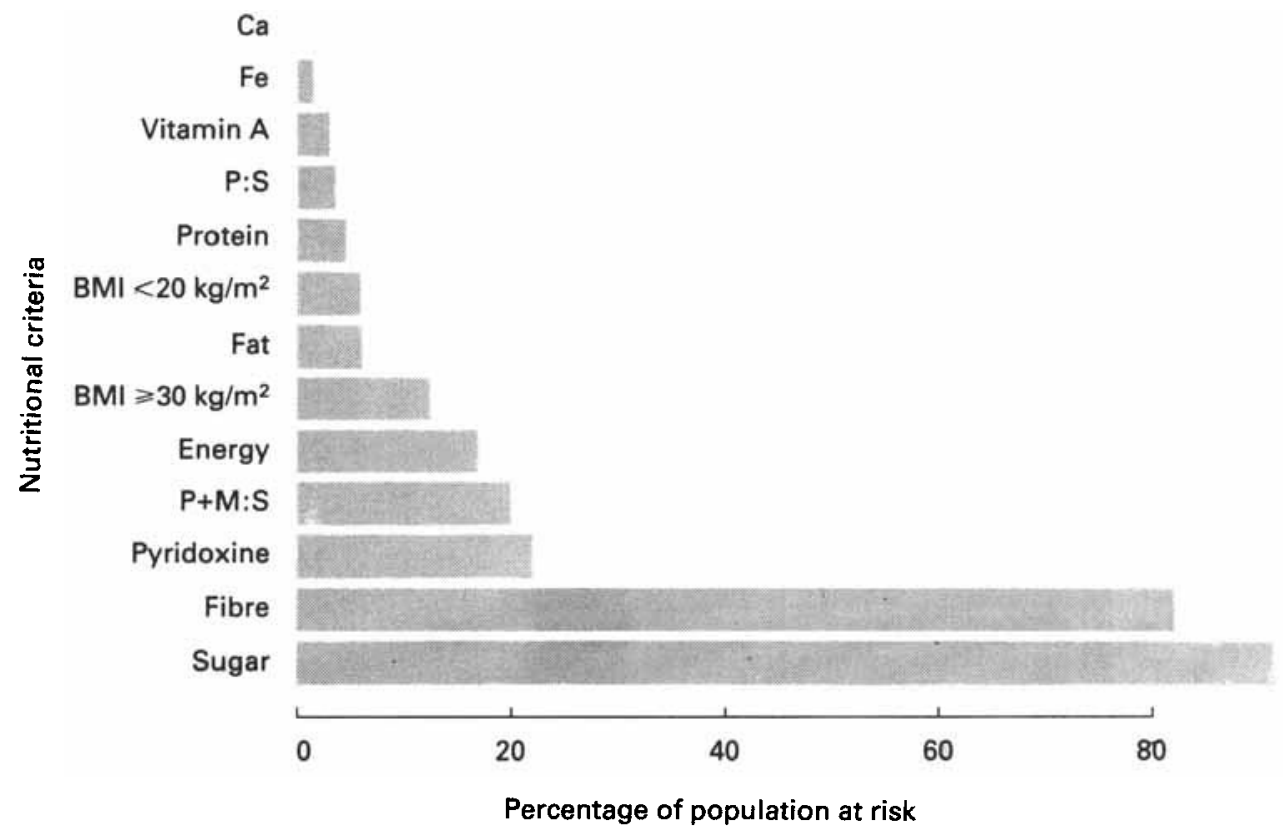

Fig. 1. Percentage of the Roskilde/Denmark population aged 70-75 years, participating in the SENECA survey (Jørgensen et al. 1991), at risk of malnutrition according to definitions of malnutrition shown in Table 1. P:S, polyunsaturated:saturated fat; $\mathrm{P}+\mathrm{M}: \mathrm{S}$, polyunsaturated+monounsaturated:saturated fat; BMI, body mass index (weight/height ${ }^{2}$ ).

\section{Health and chronic undernutrition}

The proportion of people at risk of malnutrition was different for each of the nutritional variables which were examined in the EURONUT/SENECA survey. Fig. 1 gives an example of these differences for the town of Roskilde in Denmark. Prevalence of risk of malnutrition in healthy, independent 70-75 year olds was not different from the prevalence in younger populations.

Within the elderly population there are specific groups which are at greater risk than the population at large. From a nutritional survey which we carried out in the geriatric ward of Roskilde Hospital we concluded that most of the patients were suffering from 'hospital hunger'. They were undernourished in energy, protein, fibre and most vitamins and minerals in contrast to the general elderly population.

\section{Living conditions and lifestyle and diet}

Individual variation as a result of environmental influences is relatively small in a homogeneous country like Denmark. However, from the Danish Dietary Survey (Danish National Food Agency, 1987), a few generalizations may be drawn.

(1) Those who had a fatty diet tended to be middle-aged or older, to live in Copenhagen, to be slightly overweight and to come from the poorer educated, lower social classes and to have a low income.

(2) Those who ate a sweet diet included many young and rural people. 


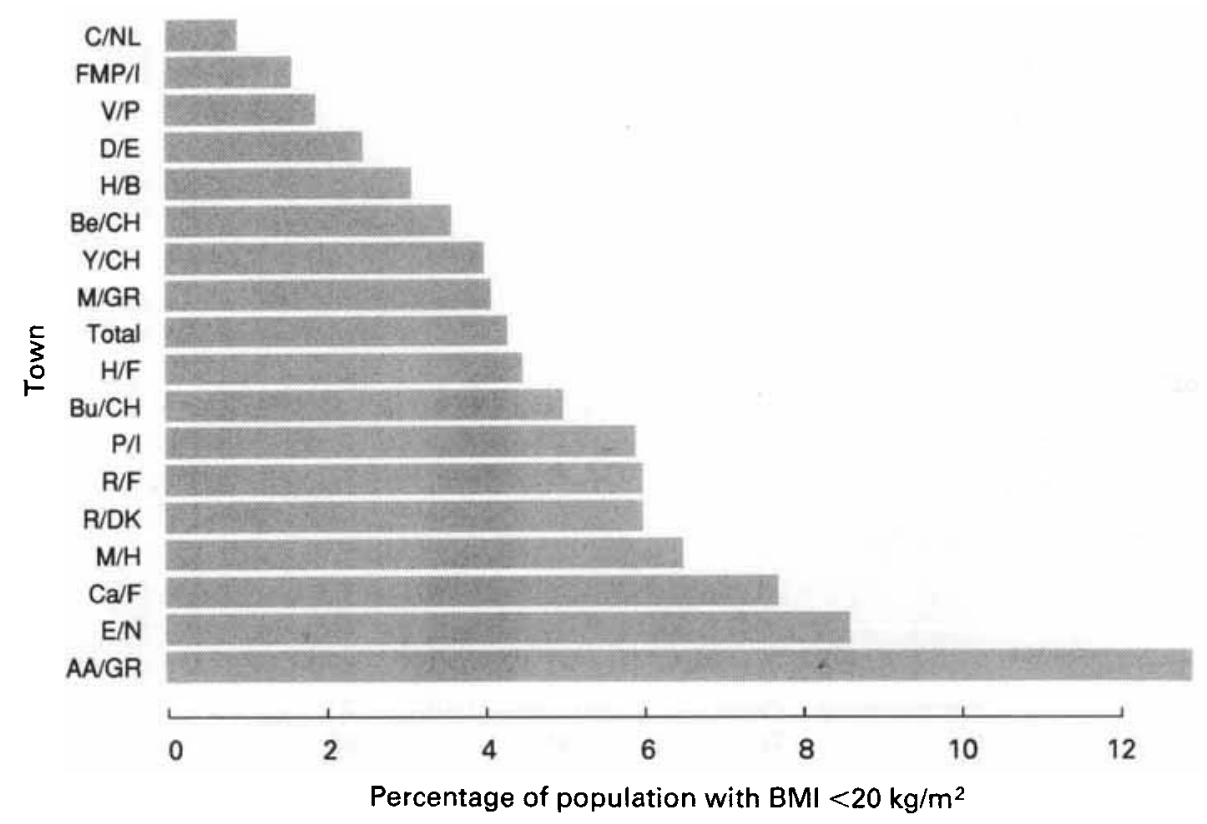

Fig. 2. Percentage of the population in each town participating in the SENECA survey (Groot et al. $1991 a, b, c, d, e$ ) with body mass index, BMI (weight/height ${ }^{2}$ ) less than $20 \mathrm{~kg} / \mathrm{m}^{2}$.

(3) Those who ate least fibre tended to have a low energy intake, to be elderly, and, among men, were well-educated, had a high income and lived in the metropolis.

(4) Among those who had low intakes of vitamins and minerals were many elderly people.

(5) Education was better than income as a means of characterizing the groups according to nutrient density of their diets. Marital status was an important determinant in men only. Differences between urban and rural, and other contrasting groups were found mainly in choice of food items, but not in energy intake or distribution of nutrients.

\section{Geography and diet}

The data obtained in the SENECA survey reflect the wide diversity of foods and diets throughout the continent of Europe, and show some of the consequences of that diversity.

Body composition. BMI $<20 \mathrm{~kg} / \mathrm{m}^{2}$. In Fig. 2 the seventeen towns participating in the SENECA survey are ranked according to the percentage of subjects with BMI less than $20 \mathrm{~kg} / \mathrm{m}^{2}$. Overall only about $5 \%$ (range 1-13\%) of those surveyed suffered from undernutrition according to this criterion (Groot et al. 1991a).

$B M I \geqslant 30 \mathrm{~kg} / \mathrm{m}^{2}$. One-fifth of people (range 10-50\%) in the survey were extremely obese according to this definition, being highest in Mediterranean countries (Groot et al. 1991a).

Generally, energy intakes were lowest in the group with BMI $\geqslant 30 \mathrm{~kg} / \mathrm{m}^{2}$ higher in the group with $\mathrm{BMI}<20 \mathrm{~kg} / \mathrm{m}^{2}$, but highest in the groups with BMI between 21 and 29.9 $\mathrm{kg} / \mathrm{m}^{2}$. 
Energy. The lower limits for energy intakes of people over 75 years old, according to Danish recommendations, are $7.7 \mathrm{MJ} / \mathrm{d}$ for men and $6.6 \mathrm{MJ} / \mathrm{d}$ for women. Overall $30 \%$ of the participants in Europe (varying in different towns from 15 to $55 \%$ ) had intakes below these limits (Groot et al. 1991b). It is hard to evaluate the adequacy of energy intake from food consumption data only, since the energy requirement of an individual is dependent on basic metabolic rate, dietary-induced thermogenesis and physical activity.

Protein. The lower recommended limits of protein intake are $49 \mathrm{~g} / \mathrm{d}$ for men and $42 \mathrm{~g} / \mathrm{d}$ for women. On average $7 \%$ of subjects were at risk, varying from $3-17 \%$ in different towns. Low protein intake was not related to low total energy intakes. The Norwegian town, for instance, had the highest percentage of energy intakes below recommended limits, but the lowest percentage of low intake of protein.

Sugar. In almost all towns more than $10 \%$ of energy intake came from mono- and disaccharides in $90 \%$ of the surveyed participants.

Fat. Of all participants $4 \%$ had a percentage fat-energy less than 50 and a saturated fat intake amounting to less than $15 \%$ of energy. In Roskilde, Denmark, $6 \%$ were in this category, but in six of the towns this value was zero.

Polyunsaturated:saturated fat (P:S). Of all participants $2 \%$ had a P:S value less than $0 \cdot 15$, but there were fewer in most Mediterranean countries and more in Switzerland, Denmark, The Netherlands and Belgium. In the latter group values for polyunsaturated plus monounsaturated fats:saturated fats $(\mathrm{P}+\mathrm{M}: \mathrm{S})$ less than 1.0 were found in more than $10 \%$ of cases.

Vitamin A. On average $40 \%$ of participants had vitamin A intakes below $600 \mu \mathrm{g} / \mathrm{d}$; in Denmark the percentage was only $5 \%$, but in all the French centres the proportion was very high (Groot et al. 1991c).

Pyridoxine. Intakes of men of less than $1.1 \mathrm{mg} / \mathrm{d}$ and of women of less than $0.9 \mathrm{mg} / \mathrm{d}$ occurred in $20 \%$ of all cases, but incidence was lower in France, The Netherlands, Belgium, Portugal and Spain.

Calcium Of the participants $7 \%$ had intakes of less than $400 \mathrm{mg} / \mathrm{d}$ on average, but low intakes did not occur at all in any of the 'cheese-countries' such as Switzerland, Norway, Denmark and The Netherlands. Incidence was up to $20 \%$ in some Mediterranean countries.

Iron The incidence of intakes of Fe below $7 \mathrm{mg} / \mathrm{d}$ in men and $5 \mathrm{mg} / \mathrm{d}$ in women was lower than $3 \%$ in most countries, but was higher, (up to $15 \%$ ) in Spain, Italy, Portugal, Greece and Hungary.

\section{Chronic undernutrition and health in the aged}

To assess the impact of chronic undernutrition on the health of elderly people, the hypothesis which was tested was that risk of poor health is greater in the group of malnourished elderly than among the rest of the elderly people. To that end the relationship between chronic undernutrition and other variables registered in the aged was investigated (Groot et al. 1991d,e). Odds ratios were calculated for a certain attribute in the malnourished persons and the rest of the population in each centre; for example, the odds ratio relating malnutrition, according to the criterion of BMI $<20$ $\mathrm{kg} / \mathrm{m}^{2}$, and physical activity on housework may be calculated as follows: 


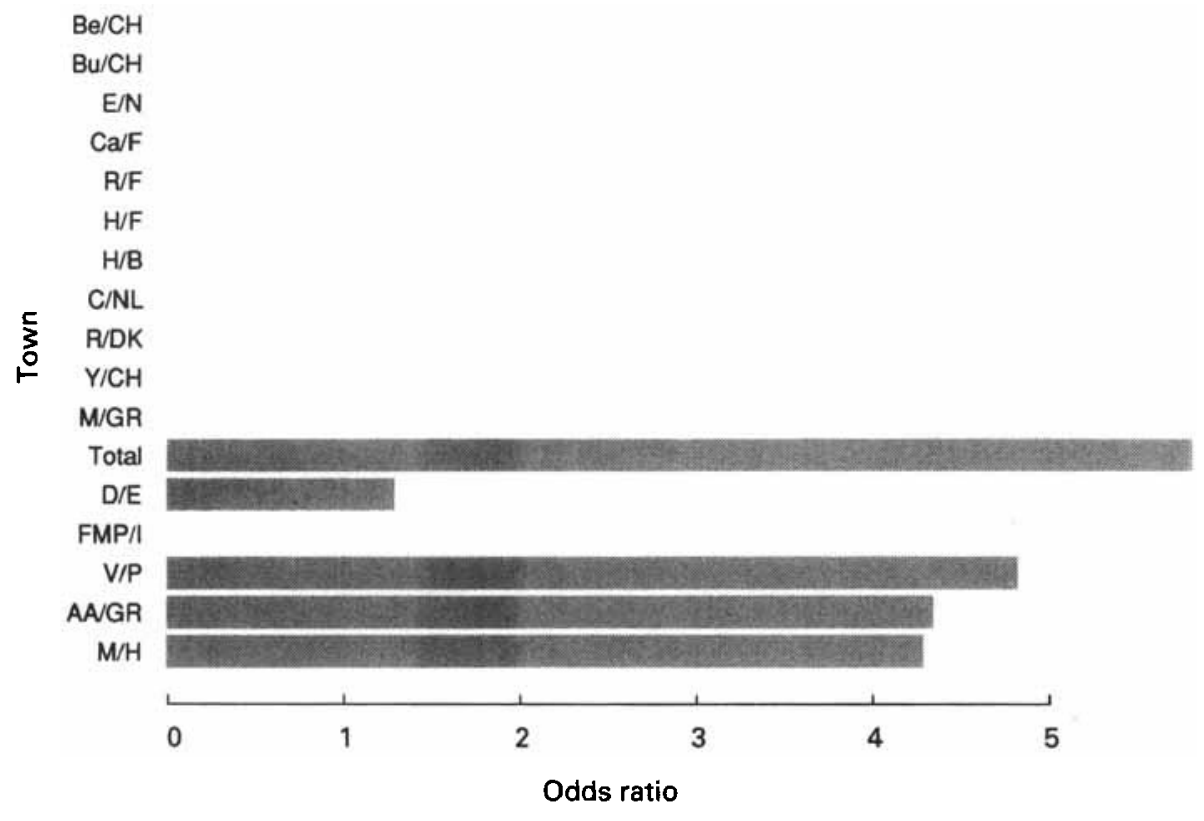

Fig. 3. Odds ratios relating low iron intakes and self-rated poor/very poor health in each of the towns participating in the SENECA survey (Groot et al. 1991a,b,c,d,e). An odds ratio $>1$ indicates that self-rated poor/very poor health is more prevalent among Fe-deficient subjects than in the rest of the subjects. For details of calculation of odds ratio, see below.

\begin{tabular}{|c|c|c|}
\hline \multirow[b]{2}{*}{$\mathrm{BMI}<20 \mathrm{~kg} / \mathrm{m}^{2}$} & \multicolumn{2}{|c|}{ Physically active } \\
\hline & Yes & No \\
\hline Yes & 10 & 1 \\
\hline No & 156 & 15 \\
\hline
\end{tabular}

$$
\text { odds ratio }=\frac{\left(\frac{10}{1}\right)}{\left(\frac{156}{15}\right)}=0.96
$$

Fig. 3 shows the odds ratios for self-rated bad health among the participants classified as malnourished with respect to $\mathrm{Fe}$ in each of the towns. The odds ratio close to 1 shows that the physical activity on housework in the risk group for undernutrition is similar to that of the rest of the sample. An odds ratio cannot be calculated if a variable has a zero value.

If there were a relationship between poor nutrition and poor health, the odds ratios should generally be substantially greater than 1, as seen in Fig. 3, where most centres with an $\mathrm{Fe}$ intake below average had an odds ratio of poor/very poor self-rated health of more than $4: 1$. 
$B M I<20 \mathrm{~kg} / \mathrm{m}^{2}$ and physical activity. In most centres the odds ratio was 1 . In France and the French-speaking centre in Switzerland it was 2-5, indicating that those who are physically active with housework tend to be leaner. There was a tendency for odds ratios relating leanness and sports activity to be high, but odds ratios relating leanness and leisure time physical activities were low.

$B M I \geqslant 30 \mathrm{~kg} / \mathrm{m}^{2}$ and physical activity. For all indicators of physical activity, during housework, sport or other leisure time activities, extremely obese subjects had odds ratios of less than 1 in almost all centres.

Protein intakes below norms and self-rated health. Odds ratios relating low protein intakes and self-rated bad health were between 1 and 14, mainly about 4 .

High sugar intake and self-rated health. Odds ratios relating high sugar intake and self-rated bad health were between 0.5 and 2 with no clear trend to indicate that high sugar consumption is associated with self-rated health. Dental health was not analysed.

High intakes of saturated fat and physical activity. Mostly the people who derived more than $50 \%$ of their energy from saturated fat were less physically active than the rest with odds ratios of less than 1 . Similarly people having low $\mathrm{P}: \mathrm{S}$ or $\mathrm{P}+\mathrm{M}: \mathrm{S}$ values had odds ratios for physical activity less than 1 .

Low intake of vitamin $A$ and self-rated health. Odds ratios of between 0.5 and 2.0 in different centres showed no clear association between low vitamin $A$ intake and self-rated health.

Low intakes of pyridoxine and self-rated health. In most centres odds ratios were between 2 and 7, indicating that bad health was associated with lower intakes of pyridoxine.

Low calcium intake and self-rated health. Odds ratios were greater than 1 in all centres ranging mainly between 2 and 4 , indicating a relationship between low $\mathrm{Ca}$ intake and bad health.

Iron and self-rated health. In most centres where Fe intake was low, the odds ratio relating $\mathrm{Fe}$ intake and poor/very poor self-rated health was more than 4.

\section{DISCUSSION}

\section{Undernutrition}

Because height is reduced over the latter stages of life, one might expect optimal BMI values to be higher in elderly populations. In the studies of Andres (1990), a BMI of 28 $\mathrm{kg} / \mathrm{m}^{2}$ was associated with the lowest mortality in 70 year olds. In population surveys a weight:height value is a fair indication of relative fatness and a predictor of morbidity and mortality. There are, however, many inherent possibilities for misclassification of individuals using BMI as a measure of undernutrition and obesity.

\section{Host factors}

Diets of elderly women appeared to be significantly more nourishing than those of elderly men. They also had a nutrient density higher than those of other age-groups. Elderly people with low energy intakes have values below lower limits for several nutrients. If the energy intake of undernourished elderly people is to be increased, energy output must be increased accordingly by encouraging physical exercise. If encouragement of physical exercise is not enough, vitamin and mineral supplements may 
be recommended. Generally the elderly in Denmark $(62 \%)$ took supplements without reason. They already had adequate intakes without further supplementation (Osler \& Schroll, 1991).

It appears from the Danish surveys and from other studies (Volkert et al. 1992), that active, healthy, mobile and independent elderly persons have a good nutritional status. Malnutrition was confined to geriatric hospital patients with disability related to multipathology, including acute flare-up of chronic disease, surgery, blood loss, cancer or infections.

\section{Agent factors}

The lower limits for energy and nutrient intakes of the Danish RDA were derived from animal studies, clinical research studies and epidemiological surveys. It was intended that when these limits are applied to results from dietary surveys subgroups of persons at risk of malnutrition would be identified. The prevalence of malnutrition in different towns and ranking orders of the towns found in the SENECA survey are probably realistic. Each subgroup, however, includes members who are not at risk. For example, some members of the lean group are physically active and have high energy intakes. On the other hand some members of the low-energy-intake group are extremely obese and are probably unable to comply with the dietary history method interview. High saturated fat or white sugar intakes are predictors of bad nutrition, not chronic undernutrition. Intakes of different vitamins and minerals differ considerably and there is a quite clear north-south trend.

\section{Diet and health}

From the calculations of odds ratios it was generally found that undernutrition, as defined, more than doubled the risk of bad self-rated health in most towns. Probably more information can be established about the interrelations between diet and health by introducing other health variables (number of chronic diseases, specific ailments and performance). The strong correlations found between diet and health in SENECA are remarkable, as cross-sectional studies seldom show strong correlations between diet and health, because of the great variation between individuals in both nutrient intake and measures of health. As shown by Liu et al. (1978) the weak associations usually found might truly be three times as strong. The predictive value of low intakes will be demonstrated when SENECA performs a follow-up study of the same participants in 1993. From the results of a longitudinal study it will also be possible to understand whether the association between diet and health means that people in Europe with low intakes of nutrients tend to be unhealthy or whether chronic diseases are the cause of undernutrition.

\section{Environment}

Epidemiological surveys yield meaningful results only when there is wide variation in the population surveyed. The great diversity in Europe of food composition and health is an important prerequisite for further analyses on socio-demographic factors of importance for the improvement of nutrition and health. 
The authors are grateful to the large group of Euronut investigators who were involved in the SENECA concerted action.

\section{REFERENCES}

Andres, R. (1990). Mortality and obesity: The rationale for age-specific height-weight tables. In Principles of Geriatric Medicine and Gerontology, 2nd ed, pp. 759-766 [W. R. Hazard, R. Andres, E. L. Bierman and J. P. Blass, editors]. New York: McGraw-Hill Inc.

Danish National Food Agency (1987). Dietary Habits in Denmark 1985. 2. Who Eats What? Danish National Food Agency Publication no. 154. Copenhagen: Danish National Food Agency.

Danish National Food Agency (1989). Nordic Recommended Dietary Allowances. Danish National Food Agency Publication no. 182. Copenhagen: Danish National Food Agency.

Groot, L. C. P. G. M., van Staveren, W. A. \& Hautvast, J. G. A. J. (1991a). Euronut-Seneca. Nutrition and the elderly in Europe. European Journal of Clinical Nutrition 45, 31-42.

Groot, L. C. P. G. M., van Staveren, W. A. \& Hautvast, J. G. A. J. (1991b). Euronut-Seneca. Nutrition and the elderly in Europe. European Journal of Clinical Nutrition 45, 105-119.

Groot, L. C. P. G. M., van Staveren, W. A. \& Hautvast, J. G. A. J. (1991c). Euronut-Seneca. Nutrition and the elderly in Europe. European Journal of Clinical Nutrition 45, 63-82.

Groot, L. C. P. G. M., van Staveren, W. A. \& Hautvast, J. G. A. J. (1991d). Euronut-Seneca. Nutrition and the elderly in Europe. European Journal of Clinical Nutrition 45, 169-182.

Groot, L. C. P. G. M., van Staveren, W. A. \& Hautvast, J. G. A. J. (1991e). Euronut-Seneca. Nutrition and the elderly in Europe. European Journal of Clinical Nutrition 45, 139-159.

Jørgensen, L. M., Kirchhoff, M., Schultz-Larsen, K. \& Schroll, M. (1991). Food and nutrition intake in Denmark, estimated by 7-day food records: I. Energy intake and distribution. II. Nutrient intake. III. Intake of vitamins, minerals and trace elements. Scandinavian Journal of Nutrition 35, 61-68.

Liu, K., Stamler, J., Dyer, A., McKeever, J. \& McKeever, P. (1978). Statistical methods to assess and minimize the role of intra-individual variability in obscuring the relationship between dietary lipids and serum-cholesterol. Journal of Chronic Diseases 31, 399-418.

Osler, M. \& Schroll, M. (1991). A dietary study of the elderly in the city of Roskilde, 1988-89. II. A nutritional risk assessment. Danish Medical Bulletin 38, 410-413.

Scrimshaw, N. S. (1989). Epidemiology of nutrition of the aged. In Nutrition in the Elderly, pp. 3-12 [A. Horwitz, D. M. Macfadyen, H. Munro, N. S. Scrimshaw, B. Steen and T. F. Williams, editors]. Oxford: Oxford University Press Limited.

Volkert, D., Frauenrath, C., Micol, W., Kruse, W., Oster, P. \& Schlierf, G. (1992). Nutritional status of the very old: Anthropometric and biochemical findings in apparently healthy women in old people's homes. Aging Clinical and Experimental Research 4, 21-28. 